\title{
Burden of Heart Failure Patients in a Tertiary Level Cardiac Hospital
}

\author{
M KABIRUZZAMAN ${ }^{\mathrm{a}}$, FN MALIK ${ }^{\mathrm{b}}, \mathrm{N}^{\text {AHMED }}{ }^{\mathrm{c}}$, M BADIUZZAMAN ${ }^{\mathrm{c}}$, SR CHOUDHURY ${ }^{\mathrm{d}}$, T HAQUE, \\ H RAHMAN ${ }^{\mathrm{a}}$, MN AHMED ${ }^{\mathrm{a}}$, D BANIK ${ }^{\mathrm{a}}$, MAM KHAN ${ }^{\mathrm{a}}$, AK DUTTA ${ }^{\mathrm{a}}$, S SAYEED ${ }^{\mathrm{f}}$, \\ RK KHANDAKER ${ }^{\mathrm{b}}$, A MALIK ${ }^{\mathrm{b}}$
}

\begin{abstract}
Summary:
Objective: Heart failure (HF) has become an increasingly frequent cause of hospital admission and carries a poor prognosis. There is a paucity of data in Indo-Asians particularly in Bangladesh on characteristics of heart failure patients. The purpose of this study was to determine the etiological factors and co-morbidity of hospitalized heart failure patients.

Method: A hospital based cross sectional study was done at a tertiary cardiac hospital in Dhaka city. Hospital medical records of 14009 patients admitted between January 2005 and August 2006 were reviewed and 1970 patients with the diagnosis of $\mathrm{HF}$ were identified. Relevant etiological information and socio demographic data were abstracted from the hospital record files.
\end{abstract}

Result: About one-seventh of total hospital admitted patient had HF. Mean age (SD) was 54.1 (15.3) years.

\section{Introduction:}

Bangladesh is passing through an epidemiological transition. Burden of infectious diseases are coming down while with increased life expectancy and wide spread change of lifestyle, non-communicable diseases are on the rise ${ }^{1}$. Cardiovascular diseases are one of

a Dr. Mohammad Kabiruzzaman MD, a Dr. Habibur Rahman MD, Dr. M Nesar Ahmed MD, Dr. Dhiman Banik MD, Dr. M A Majid Khan D-Card, Dr. Asok K Dutta MD, Assistant professor, Department of Cardiology, NHFH\&RI

b Professor Fazila-Tun-Nessa Malik MRCP, Professor R K Khandaker FRCP, Professor Abdul Malik FRCP, Professor, Department of Cardiology, NHFH\&RI

c Dr. Nazir Ahmed MD, Dr. Mohammad Badiuzzaman MD, Associate professor, Department of Cardiology, NHFH\&RI

d Dr. Sohel R Choudhury PhD, Associate Professor, Department of Epidemiology \& Research, NHFH\&RI

e Dr.Tuhin Haque PhD, Associate Professor, Department of Echocardiography, NHFH\&RI

f Dr. Sadia Sayeed MPH, Epidemiologist, Department of Epidemiology \& Research, NHFH\&RI

Address of Correspondence: Dr M Kabiruzzaman, Assistant Professor, Department of Cardiology, National Heart Foundation Hospital \& Research Institute, Plot no. 7/2, Section 2, Mirpur Dhaka 1216, Tel: 8061314-6, 8053939-6, E-mail: nhf@bdonline.com

Received: 22 April, 2009

Accepted: 11 September, 2009
Majority (35.79\%) had ischaemic heart disease (IHD) as the principal etiological factor but this frequently coexisted with a history of hypertension (46.8\%). Hypertension was considered the primary risk factor of HF in $29.14 \%$ of cases. Hypertension alone and in coexistence with other etiology was found in $48.07 \%$ (947) cases. Diabetes Mellitus (DM) co-existed with IHD in $41.4 \%$ (292) and it (32.64\%) was found more prevalent in Dilated Cardiomyopathy (DCM) patient with HF.

Conclusions: The mean age of hospitalized HF patients is remarkably lower than other related studies done abroad. The single most common etiology for $\mathrm{HF}$ is ischemic heart disease in this population. Hypertension is the most common risk factor. Measures to prevent ischaemic heart disease and control of risk factors are essential to prevent premature onset of $\mathrm{HF}$.

(J Bangladesh Coll Phys Surg 2010; 28: 24-29)

the main causes of morbidity and mortality in this country now. Heart failure (HF) is a significant and growing health problem as the population ages. Despite improvements in therapy, mortality and morbidity remain high ${ }^{2}$. In the United Kingdom, most patients admitted to hospital with HF are more than 65 years old and remain inpatients for a week or more . Prevalence of heart failure rises from around $1 \%$ in the age group 50-59 years to between 5 and $10 \%$ of those aged $80-89$ years ${ }^{3}$. Heart failure is frequently due to coronary artery disease, tends to affect elderly people and often leads to prolonged disability. Although the outlook depends to some extent on the underlying cause of the problem, heart failure carries a very poor prognosis, approximately $50 \%$ of patients with severe HF due to severe left ventricular dysfunction will die within 2 years ${ }^{3}$. Hospitalized heart failure is regarded as prognostically more adverse with a high mortality and readmission rate .However, there is a paucity of data on outcomes of heart failure in particular in IndoAsians ${ }^{4}$.

There is an ever increasing number of hospital admissions due to heart failure in different hospitals 
in Bangladesh, however there is a paucity of data on characteristics of the patients in terms of demographic and etiological information. It is important to identify the etiological factors associated with HF in this population to determine strategy for prevention and early detection. In this study we sought to determine the disease burden of heart failure patients and the age and sex specific prevalence of heart failure among patients admitted into NHFH\&RI and to identify the etiological pattern of diseases leading to heart failure with associated comorbid factors.

\section{Materials \& Method:}

Settings: This was a single center cross sectional study carried out at National Heart Foundation Hospital \& Research Institute (NHFH\&RI), a tertiary teaching hospital in Dhaka, Bangladesh. This centre receives a mixture of affluent and low-middle income patients and serves the entire country as a referral center for patients requiring high-intensity tertiary care.

The hospital medical records from January 2005 to August 2006 were searched \& all patients suffering from heart failure were included in this study. Variables recorded includes age, sex, history of Diabetes Mellitus (DM) (defined as a fasting glucose $\geq 126 \mathrm{mg} / \mathrm{dl}$ or on treatment), Hyperlipidemia (fasting cholesterol $\geq 200 \mathrm{mg} / \mathrm{dl}$ or on treatment), hypertension (blood pressure $\geq 140 / 90 \mathrm{mmHg}$ or on treatment). Associated co-morbidity were classified into some major group of heart diseases: old myocardial infarction (OMI), acute coronary syndrome (ACS), dilated cardiomyopathy (including ischaemic and other causes), valvular heart diseases, hypertensive heart disease, congenital heart diseases. Among the ACS were acute myocardial infarction (AMI), recent myocardial infarction (RMI), and unstable angina (UA).

Coronary artery disease was considered the primary aetiology if the patient had a documented history of myocardial infarction (acute or in the past); unstable angina pectoris; a history of stable angina ; or coronary artery disease confirmed at coronary angiography. Such cases were subdivided into those with acute cardiac ischaemic syndromes (acute myocardial infarction or unstable angina pectoris), and those without. Hypertension was considered the aetiology if there was a history of hypertension from the general practice records or sustained hypertension (blood pressure greater than 140/90 $\mathrm{mmHg}$ ) during hospital admission and there was no documented history of myocardial infarction or angina, and no evidence of other cardiac pathology. The presence and severity of underlying valvular heart disease was assessed from the history, clinical examination and echocardiographic findings. The presence of cardiac arrhythmias was noted and the temporal relationship of these to the development of heart failure ascertained. Data were checked for completeness and consistencies. The descriptive statistics were analysed with SPSS for windows version 12.5.

\section{Results:}

Among 14,009 total admitted patients throughout this period 1970 patients were found to have a diagnosis of heart failure ie $14.1 \%$ of totally admitted patients had heart failure. The mean age of these patients were 54.1 \pm 15.3 years ranging from 1 to 95 years with a high preponderance of males. The majority of the patient population was in the age group of 51- 60 years (30.7\%) (Table I). $71.7 \%$ of the cases were male \& $28.3 \%$ female by gender specification. Chronic heart failure patients were more prevalent among the patient population ( $71.3 \%$ chronic Vs $28.7 \%$ acute). Coronary artery disease was found to be the common cause of heart failure in adult population $(n=705,35.79 \%)$.

Majority of the ACS patients were diagnosed as AMI $(\mathrm{n}=400,20.3 \%)$. Among total study population, $49.4 \%(n=974)$ patients were hypertensive and $18.8 \%$ $(n=371)$ patients were diabetic. 29.14\% $(n=574)$ patients had hypertensive heart disease leading to heart failure. The patients with heart failure having coronary artery disease $(n=705)$ had hypertension $(\mathrm{n}=330,46.8 \%)$ as the most prevalent major risk factor; diabetes was found to be second common comorbid factor. Patients with dilated cardiomyopathy $(\mathrm{n}=242)$ had DM $(\mathrm{n}=79 ; 32.64 \%)$ as most prevalent comorbid factor. Among the congenital heart diseases, ventricular septal defect (VSD) and patent ductus arteriosus (PDA) were most common cause of heart failure needing hospitalization (Table 2).

Mortality rate of the study population were $9.7 \%$ and was higher among males (10.6\% vs. $7.7 \%)$ than females. 


\section{Table-I}

Age and Sex distribution of heart failure patients admitted in NHFH\&RI from January 2005 to August 2006 (n=1970)

\begin{tabular}{lcc} 
Age group (years) & Number & $\%$ \\
\hline$\leq 30$ & 169 & 8.6 \\
$31-40$ & 204 & 10.4 \\
$41-50$ & 389 & 19.5 \\
$51-60$ & 604 & 30.7 \\
$61-70$ & 388 & 19.7 \\
$71-80$ & 165 & 8.4 \\
$\geq 81$ & 51 & 2.6 \\
Sex & Number & $\%$ \\
Male & 1413 & 71.7 \\
Female & 557 & 28.3 \\
\hline
\end{tabular}

\section{Table-II}

Distribution of study population by their etiological disease pattern \& associated co-morbid factors $(n=1970)$

\begin{tabular}{|c|c|c|c|c|c|}
\hline \multirow{2}{*}{\multicolumn{2}{|c|}{ Morbidity type }} & \multirow[t]{2}{*}{ No. of cases } & \multirow[t]{2}{*}{$(\%)$} & \multicolumn{2}{|c|}{ Co-morbid Factors } \\
\hline & & & & HTN & $\mathrm{DM}$ \\
\hline \multirow[t]{5}{*}{ CAD } & & 705 & 35.75 & $330(46.8 \%)$ & $292(41.4 \%)$ \\
\hline & Old MI & 305 & & 150 & 125 \\
\hline & AMI & 305 & & 78 & 75 \\
\hline & RMI & 82 & & 27 & 36 \\
\hline & UA & 114 & & 75 & 56 \\
\hline \multicolumn{2}{|c|}{ Hypertensive heart disease } & 547 & 29.14 & & \\
\hline \multicolumn{2}{|c|}{ Dilated cardiomyopathy } & 242 & 12.28 & $70(28.93 \%)$ & $79(32.64 \%)$ \\
\hline \multicolumn{2}{|c|}{ Valvular heart disease } & 437 & 22.18 & & \\
\hline \multicolumn{2}{|l|}{ Others } & 12 & 0.6 & & \\
\hline
\end{tabular}

Table-III

Comparison of etiological factors in different studies in different territories

\begin{tabular}{|c|c|c|c|c|c|c|}
\hline \multirow[t]{2}{*}{ Etiology } & \multirow[t]{2}{*}{$\begin{array}{l}\text { Teerlink et al, } \\
31 \text { studies, } \\
1989-9015\end{array}$} & \multicolumn{3}{|c|}{$\begin{array}{c}\text { Framingham } \\
\text { Heart Study } 15 \\
\text { USA }\end{array}$} & \multirow[t]{2}{*}{$\begin{array}{l}\text { Hillingdon } \\
\text { Study 5,15 } \\
\text { West London }\end{array}$} & \multirow[t]{2}{*}{$\begin{array}{c}\text { NHFH\&RI, } \\
\text { Kabiruzzaman et al, } \\
\text { Bangladesh }\end{array}$} \\
\hline & & Men & & Women & & \\
\hline IHD & 50 & 59 & & 48 & 36 & 35 \\
\hline Hypertension & 4 & 70 & & 78 & 14 & 29 \\
\hline Idiopathic & 18 & - & & - & - & - \\
\hline Valvular & 4 & 22 & & 31 & 7 & 22 \\
\hline DCM & - & - & & - & 12 & \\
\hline Unknown & 13 & - & & - & 34 & - \\
\hline Other & 10 & 7 & 7 & 10 & 0.6 & \\
\hline $\mathrm{AF}$ & - & - & & - & 5 & - \\
\hline
\end{tabular}

$\mathrm{DCM}=$ Dilated cardiomyopathy. $\mathrm{IHD}=$ Ischemic heart disease.

$\mathrm{AF}=$ Atrial Fibrillation. (--) = Not mentioned as etiology. 
Table-IV

Age of heart failure patients in different territories of the World

\begin{tabular}{ll}
\hline$>$ Hillingdon study, West London 5, & Median age $=76$ years \\
$>$ ESC countries 10, & Mean age $=75$ years \\
$>$ Framingham Heart study, USA8, & Mean age $=70$ years \\
$>$ Seow et al, Singapore 6, & Mean age $=68$ years \\
$>$ Jafary et al, Pakistan 4, & Mean age $=61$ years \\
$>$ Kabiruzzaman et al, NHFH\&RI, Bangladesh, & Mean age $=54$ years \\
\hline
\end{tabular}
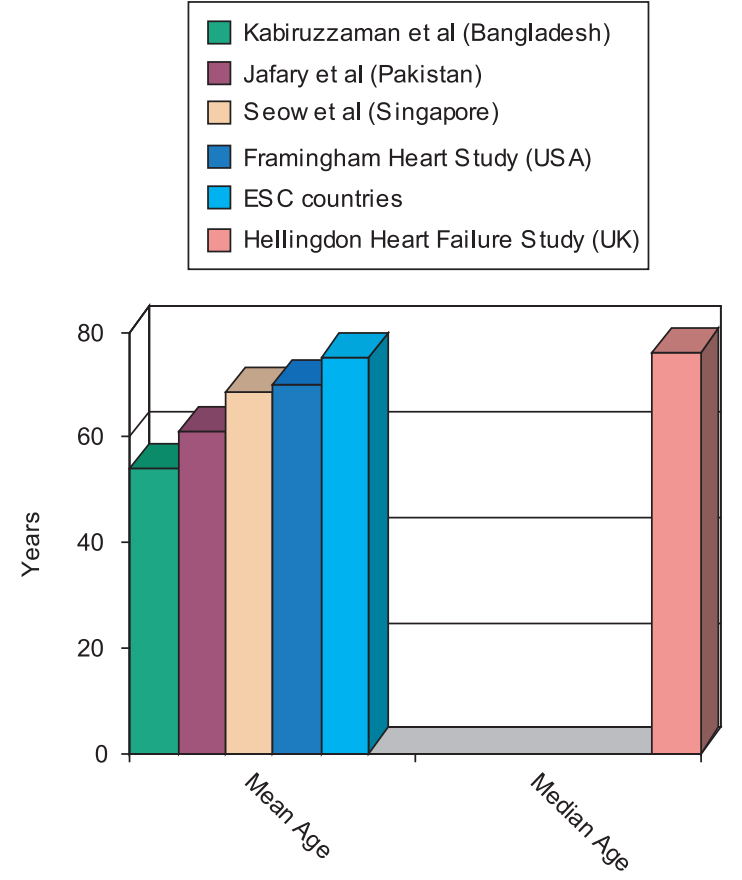

Fig.-1: Mean and median age of heart failure patients in different studies

\section{Discussion:}

Clinical survey of heart failure in the general population is uncommon. Much of our current knowledge of heart failure is based on highly selected hospital series, or patients selected for clinical trials. Such patients do not reflect the spectrum of heart failure as it presents in the population.

Our study shows that mean age of hospitalized heart failure patients was $54.1 \pm 15.3$ years with higher prevalence in male than female and coronary heart disease being most common cause of heart failure. The mean age of our heart failure population is remarkably lower than that observed in different studies done abroad ${ }^{3-10}$. The possible reasons for premature onset of heart failure may be lack of awareness of morbid risk factors and appropriate treatment. It has been reported that Asians may be less compliant with medication, perhaps because of distrust of western medicine and different cultural views ${ }^{11}$.

Hypertensive heart disease leading to heart failure was found in $29.14 \%$. This was second common cause of $\mathrm{HF}$ in our study. In addition to producing a pure form of hypertensive cardiomyopathy, hypertension is a major risk factor for heart failure from any cause ${ }^{2}$.

In the United Kingdom, most patients admitted to hospital with heart failure are more than 65 years old. The prevalence of heart failure rises from around $1 \%$ in the age group 50-59 years to between 5 and $10 \%$ of those aged 80-89 years. Heart failure is frequently due to coronary artery disease ${ }^{3}$.

The Hillingdon heart failure study evaluated the incidence and aetiology of heart failure in one district of west London, England using clinical and echocardiographic data and a case definition based on three cardiologists applying the ESC definition of heart failure The median age at the time of diagnosis of heart failure was 76 years. The incidence of heart failure was significantly higher in men than women at all ages with an age-standardised ratio of 1.75 . The primary aetiologies were coronary heart disease (36\%), unknown (34\%), hypertension (14\%), valve disease $(7 \%)$, atrial fibrillation alone $(5 \%)$, and other $(5 \%)^{5}$.

Seow et al studied 225 patients in Singapore with LVEF $\leq 40 \%$, their mean age \pm SD was $68.5 \pm 12.3$ years and more than $51.1 \%$ of the subjects were aged 70years and more. The most common cause of HF 
was coronary heart disease (85.5\%). Co morbid medical conditions were prevalent in this cohort, with $83.5 \%$ having at least one co-morbid condition. Hypertension was the most prevalent co-morbid condition; affecting $60 \%$ of the patients; followed by diabetes mellitus $(56.9 \%)^{6}$.

In Pakistan, Jafary et al studied 196 patients with mean age \pm SD $61.2 \pm 12.8$ years with a high preponderance of males. All of them were suffering from systolic heart failure with LVEF $\leq 40 \%$, requiring hospital admission with more than $60 \%$ suffering from hypertension $(67.3 \%)$ and diabetes mellitus $(60.7 \%)$ and more than three-fourths having a history of coronary artery disease in the past 4.

In the United States, it is primarily a disease of ageing, with over $75 \%$ of existing and new cases occurring in individuals over 65 years of age ${ }^{7}$. In the USA, the Framingham heart study has reported the mean age at the time of diagnosis of heart failure was 70 years. The incidence of heart failure to be $0.3 \%$ per annum in men and $0.2 \%$ per annum in women aged 50-59 years; rising by a factor of 10 to $2.7 \%$ per annum in men and $2.2 \%$ per annum in women aged 80-90 years. The incidence of heart failure was significantly higher in men than women at all ages with an age-standardized incidence ratio of $1.67^{8}$

Mcmurray et al studied trends in hospitalization for heart failure in Scotland 1980-1990. They found seventy-eight percent of discharges were in persons aged $\geq 65$ years and $48 \%$ of discharges were male ${ }^{9}$

Remes et al studied incidence of heart failure in 45 74 year old inhabitant in four rural communities in Eastern Finland. The incidence rates of heart failure increased with age in both sexes. Coronary heart disease or hypertension was evident in $80 \%$ cases 12 .

This is a single centre retrospective cohort study and our results may not be extrapolated to the entire Bangladeshi population. However, our hospital provides services to a wide mix of patients, ranging from affluent to poor, somewhat reflective of the population at large throughout Bangladesh. Because of the retrospective nature of the study several important variable are missing in our study including reliable documentation of sign and symptoms as well as anthropometric values. We could not determine co- morbid illness like COPD, renal functional impairment, obesity.

Heart failure is a significant and growing health problem as the population ages. About one-seventh of total hospital admitted patients had heart failure. The mean age $(54.1 \pm 15.3)$ of our heart failure patients was significantly lower than the other studies done abroad (Table-4). Coronary heart disease (with or without hypertension) should be the dominant aetiology of heart failure in the Bangladesh. In this study the single most common aetiology was ischaemic heart disease $(35.79 \%)$ and past history of hypertension was common (48.07\%). This is very similar to the findings in the heart failure study done in Hillingdon (West London) 5, Finland 12 and Sweden ${ }^{13}$ and is not dissimilar to that reported from Framingham study ${ }^{14}$ (Table-3). The number of patients with heart failure is bound to rise at the premature age if appropriate measurement is not taken to manage risk factors and to increase public awareness. Clinical and Epidemiological study is needed to explore further details.

\section{References:}

1. Ministry of Health and Family Welfare, Government of People's Republic of Bangladesh. Strategic plan for Surveillance and Prevention of Noncomunicable Disease in Bangladesh 2007-2010. 2007, Dhaka

2. Dar O, Cowie MR. 2008. The Epidemiology and Diagnosis of Heart Failure. In: Fuster V, Walsh RA, O'Rourke RA, Poole-Wilson P (eds). Hurst's The Heart. 12th ed. McGrawHill, New York, pp. 713-721.

3. Bloomfield P, Bradbury A, Grubb NR, Newby DE. 2006. Cardiovascular disease. In: Boon NA, Colledge NR, Walker BR, Hunter JAA (eds). Davidson's Principles and Practice of Medicine, 20th ed. Churchill Livingstone, Edinburgh, pp. 519-644.

4. Jafary FH, Kumar M, Chandna IE. Prognosis of hospitalized new- onset systolic heart failure in Indo-Asians- A lethal problem. J Cardiac Fail 2007; 13:855-860.

5. Cowie MR, Wood DA, Coats AJ, et al. Incidence and aetiology of heart failure: a Population-based study. Eur Heart J 1999; 20:421-8.

6. Seow SC, Lee YP, Chan YH, et al. Heart Failure Mortality in South Asian Patients With Left Ventricular Systolic Dysfunction. J Cardiac Fail 2007; 13:476-481.

7. Bashore TM, Granger CB, Hranitzky P. 2007. Heart. In: McPhee SJ, Papadakis MA, Tierney LM (eds). Current Medical Diagnosis and Treatment, 46th ed. McGraw Hill, New York, pp. 316-428. 
8. Ho KK, Pinsky JL, Kannel WB, et al. The epidemiology of heart failure: the Framingham study. J Am Coll Cardio 1993; 22(4 suppl A):6A-13A.

9. McMurray J, McDonagh T, Morrison CE, Dargie HJ Trends in hospitalization for heart failure in Scotland 19801990. Eur Heart J 1993; 14:1158-62.

10. The Task Force for the Diagnosis and Treatment of Acute and Chronic Heart Failure 2008 of the European Society of Cardiology. ESC Guidelines for the diagnosis and treatment of acute and chronic heart failure 2008. European Journal of Heart Failure dol:10.1016/j.ejheat.2008.08.005

11. Sung CL. Asian patients' distrust of western medical care: one perspective. M Sinai J Med 1999; 66:259-61.
12. Remes J, Reunanen A, Aromaa A, Pyorala K. Incidence of heart failure in Eastern Finland: a population-based surveillance study. Eur Heart J 1992; 13: 588-93.

13. Eriksson H, Svarsudd K, Larsson B et al. Risk factors for heart failure in the general population: the study of men born in 1913. Eur Heart J 1989; 10: 647-56.

14. Kannel WB, Pinsky J, Trends in cardiac failure- incidence and causes over three decades in the Framingham study (Abstr). J Am Coll Cardiol 1991; 17: 87A.

15. Lip GYH, Gibbs CR, Beevers DG. ABC of heart failure, Aetiology. BMJ Volume 3208 January 2000. www.bmj.com 